\title{
Social climate of cities as a factor of economic growth (on the example of the city of Kerch).
}

\author{
Zaitsev A.B. ${ }^{\mathrm{a}, \mathrm{b},}$ *, Lazareva I.V. ${ }^{\mathrm{a}}$, Melnikova G.L. ${ }^{\mathrm{a}}$ \\ ${ }^{a}$ Tsniip of the Ministry of construction of Russia, abz.8@mail.ru, olganti@yandex.ru \\ ${ }^{b}$ Tsniip of the Ministry of construction of Russia, buddha5@mail.ru \\ * Corresponding author
}

Keywords: urban planning, GIS technology, the city of Grado-social studies, Crimea, sociology, architecture, cultural geography.

\section{Abstract:}

One of the ways to solve the problem of improving economic theory is the development of methods of socio-economic analysis using urban planning theories and geoinformation technologies. The article considers one of such approaches on the example of the city of Kerch.

The phenomenon of urbanization is a universal phenomenon, it is observed throughout the globe and in all developed countries. More and more people are moving and living in megacities, large and medium-sized cities. However, despite the fact that the modern wave of urban growth is unprecedented, history indicates that in ancient times there were periods of rapid development of cities, followed by recessions. As for our country, the dynamics of the resettlement system and the policy that is being pursued in this direction are of great importance now. Will our country be able to attract people to large cities, or will there be growth in the rural population and small towns? The state of society will largely depend on this. The position we will take in this area of knowledge and activity will determine the basis for confronting global challenges. One of the leading areas will be the engineering modernization of rural settlements and social rehabilitation of highly urbanized areas.

Spatial differentiation of social structures is important for understanding economic processes in society. Their research is at the intersection of geographical, urban and social scientific disciplines. Study aspects of social processes in urban planning was engaged scientists like Yargina Z. N., Shvidkovsky D. O., Lezhava I. G., Nekrasov A. B., Kogan L. B., Dridze T. M., Romm A. P., Tovmasyan E. O., Vilner M. Ya., Lazarev I. V., Aurov V. V., DYKHOVICHNY Y. A., Efimov A.V., Vilner M. Ya., Strel'nikov A. I., Kogan L. B., Kudryavtsev, A. P., O. R. Mamleev, , Podolsky V. I., L. SankinaL., Stepanov A.V., V. G. Talkovsky, Puppies A. S., K. K., Khachatryan. B. V., Handelsman and others.

In sociology and urban planning there are a number of terms that characterize the social processes of cities:

the social fabric of the city is social interactions in space [1]. (The concept was first introduced by sociologist Simmel. In General, the society is a "fabric" woven of innumerable interactions for the land).

social zoning-is the distribution of land in the city in accordance with the indicators of their social characteristics and taking into account their combination.

Social climate-a term that means the General direction of development of any community as a whole or part of it. [2]. The climate is socio-psychological-integral characteristic of the system of interpersonal relations in the group [3].

The social climate has its own laws of development and influence. Where there are conflicts and stress, to spend less resources on the solution of necessary tasks: it allows you to save money and resources. Where the socio-psychological atmosphere is more favorable qualitative processes of life. A favourable social environment is also a powerful factor in attracting both people and investment. Slum depressive areas are well known in large cities, which are repelled by their social climate and, on the contrary, even economically underdeveloped cities, which maintain a healthy sociopsychological climate, are attractive for tourists and new immigrants.

The social climate is also one of the factors of migration, which fundamentally affects the stability of peace and harmony in interethnic and interreligious relations. The relevance of the issue is confirmed by the Concept of the state migration policy of the Russian Federation for the period up to 2025 approved on October 31, 2018. This document States that it defines "the purpose, principles, objectives and main directions of the state migration policy".

It is separately indicated that the concept is developed taking into account a number of strategies, including the Strategy of socio-economic development of the Far East and the Baikal region, as well as the forecast of long-term socio-economic development of the Russian Federation until 2030 [4].

The purpose of the updated migration policy is announced: 1 . Security of the state; 2 . Maintenance of interethnic and interreligious peace; 3. Preservation of Russian culture, Russian language and historical and cultural heritage of the peoples of Russia; 
All of the above once again emphasizes the relevance of urban social research and the importance of research on the social climate of cities.

In the socio-urban theory, socio-climatic conditions can be divided into unfavorable, neutral and favorable. Their state can change in time and space.

The formation and distribution of the social climate depends on three main groups of factors: geographical, urban planning and socio-economic. The classification of the social climate, the development of methods for its monitoring, study and forecasting is a rather complex task.

The classification can be based on various sociological and sociometric methods and diagnostics. Due to the great complexity and multifactorial processes of formation of the social climate, diagnostic techniques and classification approaches are being refined and improved.

To study the social climate, the author proposes a method of geoinformation analysis of the social climate of urban systems, based on digital, grid display of social indicators, by analogy with the digital elevation model and statistical data model. Theoretical developments of these methods were engaged in scientists such as Tikunov Vs, Samsonov Ie and others [5].

It is obvious that the formalization and visualization (in the form of geoinformation model) of the influence of the type of development and historical and cultural heritage on the social characteristics of cities is important in the study. The objectives of the study is to select the characteristics that are important for assessing the quality of the urban environment and social parameters. As well as the analysis of their structure, and their correlation with each other, in order to identify the relationship "city" and "population".

One of the priorities in our country is the development of the Crimean Peninsula, which has returned to Russia. Socioeconomic integration into the space of Russia and the maintenance of peace and harmony in its territory puts the problem of studying the social climate on a priority position. One of the most important centers in the Crimea, taking into account the newly formed geopolitical and logistical circumstances, is the city of Kerch. This city is the gateway to Tavrida. In the future, this city will bear the main burden of tourist flows and transit cargo.

\section{Bibliography:}

1. Gromov I. A., Matskevich A. Yu., Semenov V. A. the Western theoretical sociology. // SPb. One thousand nine hundred ninety six

2. Meshcheryakov, B., Zinchenko, V. p. Great psychological dictionary, St. Petersburg, Russia.: PrimeEurosign, 2003. - 632 p.

3. Parygin B. D. Social-psychological climate of the team: ways and methods of study // edited by V. A. Yadov. - SPb., "Science", 2006.

4. Vladimir Solovyov Vladimir Putin approved a new Concept of migration policy // source: Kommersant online journal Electronic resource URL: https://news.mail.ru/politics/35231128/?frommail=1 (accessed 02.11.2018 G.)

5. Tikunov V. S. fundamentals of Geoinformatics: 2 kN.: textbook for University students / and others; ed. V. S. Tikunov. - Moscow: publishing center "Academy", 2004. - kN. 2. - 480 p. 